\section{EL CONTROL SELECTIVO DE LAS FRONTERAS Y LA TRANSNACIONALIZACIÓN DE SUS RESISTENCIAS}

\author{
Iker Barbero González \\ Universidad del País Vasco \\ Euskal Herriko Unibertsitatea
}

\begin{abstract}
This article deals with an emergent phenomenon, the transnational networks in advocacy of immigrants' rights. As a conjunction of multiple organizations (immigrant associations, NGOs, anti-globalization groups, trade unions...), these networks have realised the necessity of transnationalizing their action in order to defeat the European Union neoliberal policies of border control and labour supply.
\end{abstract}

KEY WORDS: European Union; border control; transnational networks; immigrants' rights.

\section{La CONStRUCCIÓN DE UN Estado tRANSNACIONAL DE CONTROL SELECTIVO DE LA INMIGRACIÓN EN LA UNIÓN EUROPEA}

En un artículo de 2001, titulado El mundo después del 11-S, Ulrich Beck auguraba "una nueva era de cooperación transnacional" para combatir las múltiples amenazas que la globalización entraña para la seguridad nacional, entre las que destacaba el terrorismo global, además de las catástrofes climáticas, las migraciones, las sustancias nocivas en los alimentos, la delincuencia organizada, etc. (Beck, 2001). Este autor consideraba que estos "Estados transnacionales cooperantes" podían desglosarse en dos tipos ideales de cooperación estatal transnacional: los Estados cosmopolitas y los Estados de vigilancia transnacional. Mientras que los primeros optarían por una desnacionalización de los espacios de discusión y decisión con el objetivo de integrar libremente las múltiples visiones derivadas de la diversidad cultural, religiosa o lingüistica fruto de la globalización; los segundos representarian el intento de construir una ciudadela occidental contra aquéllos que consideramos terroristas y que pertenecen a la otra cultura. "Estados fortaleza en los que la seguridad y lo militar se escriben con mayúscula, y la libertad y la democracia, con minúscula" (idem).

\section{THE SELECTIVE CONTROL OF FRONTIERS AND ITS TRANSNATIONAL RESISTENCES}

RESUMEN: Este artículo trata un fenómeno relativamente reciente: las redes transnacionales por los derechos de los inmigrantes. Refiere a la confluencia de múltiples organizaciones (asociaciones inmigrantes, ONGs, grupos anti-globalización, sindicatos, etc.), quienes son conscientes de la necesidad de transnacionalizar sus acciones de cara a contrarrestar las políticas neoliberales de control de fronteras y provisión de mano de obra provenientes desde la Unión Europea.

PALABRAS CLAVE: Unión Europea; control de fronteras; redes transnacionales; derechos de los inmigrantes.

Sin embargo, a diferencia del terrorismo global, en lo que se refiere a las migraciones internacionales hacia el Norte, no ha sido necesario ningún ataque global para percatarse de tal tendencia. En los últimos 20 años, la construcción europea, en materia de migraciones internacionales, ha tomado un rumbo claro: la cooperación entre agentes, estatales y privados, para el control selectivo de aquellas personas no comunitarias que opten por adentrarse en el territorio europeo. Las denominadas políticas de integración, salvo contadas excepciones, han tenido siempre un papel secundario y meramente formal. Al menos no han tenido el apoyo institucional ni económico que han tenido las políticas de control. Las bases iniciales para la construcción del entramado institucional, administrativo y policial se sentaron a mediados de los 80 , en el seno del Grupo de TREVI ${ }^{2}$ por un lado, con la elaboración del Tratado de Schengen, por el cual se abolían las fronteras internas de los Estados comunitarios, y por otro, en la comisión ad hoc, encargada de actualizar el sistema de puestos fronterizos exteriores, la coordinación de políticas de visados y combatir la falsificación. Desde entonces, hemos asistido a la concreción del control de flujos a través de lo que, siguiendo a Balibar ${ }^{3}$, se podrian denominar tres "frentes de fronteras": exteriores, exteriorizadas e internas ${ }^{4}$. Las fron- 
teras exteriores de la UE son aquéllas trazadas por confines y muros anti-persona, gestionadas por agencias (Frontex) y vigiladas por sofisticados sistemas de vigilancia (SIVE) en manos de los diferentes cuerpos policiales y militares de los Estados miembro. Las fronteras exteriorizadas, que representan la novedad en el control de flujos migratorios, suponen externalizacion literal de las fronteras a los paises de origen y de tránsito, invadiendo su soberanía a cambio de cooperación al desarrollo ${ }^{5}$, mediante instrumentos como los sistemas de visados (SIS o SIS II), el control privado por las agencias de viaje o los campos de retención situados en los paises colindantes denominados "zona de contención". Finalmente, las fronteras internas, eliminadas para los ciudadanos comunitarios, pero elevadas para los extracomunitarios, se manifiestan a través de los tediosos trámites burocráticos para la obtención de permisos, los checkpoint policiales en las estaciones de trenes y autobuses, los centros de internamiento o las órdenes de expulsión. Todas estas fronteras, y muchas más, delimitan la ciudadela transnacional europea.

Sin embargo, no se trata de una fortaleza hermética, sino que se sirve de mecanismos selectivos a través de los cuales satisfacer las necesidades de mano de obra que demanda el Mercado ${ }^{6}$. Siguiendo las pautas de transformación jurídicas de la globalización -informalidad, neo-regulación, flexibilidad, etc. (Faria, 2000)-, una nueva normativa ad hoc es la encargada de regular las migraciones "deseadas" con el objetivo que ésta resulte adaptable a las fluctuaciones del Mercado. Nos encontramos ante lo que Cohen ha denominado "la división transnacional de la mano de obra" (2006), es decir, la creación de un sistema económico transnacional de suministro de trabajadores migrantes allá donde sean requeridos: fábricas-maquilas en el Sur e invernaderos o servicios en las grandes ciudades del Norte. Ya sea a través de mecanismos potenciados por los Estados miembros como los sistemas de cuotas, contratación en origen, acuerdos bi(multi)laterales o cuerpos jurídicos totalmente transnacionalizados como el GATS -Acuerdo General Sobre el Comercio de Servicios- de la Organización Mundial del Comercio, las migraciones internacionales se han convertido en un suministro global de trabajadores a la carta. La "deslocalización in situ" que dice Terray (1999). Una mano de obra empleada en aquellos sectores como la construcción, la agricultura, el cuidado a domicilio o la hostelería que no son posibles de trasladar a paises del Sur.
En definitiva, el objetivo es crear un sistema regulatorio de las migraciones acorde a la confluencia de dos principios: el control y la provisión de mano de obra. El ejemplo institucional más paradigmático es el "Pacto Europeo sobre Inmigración y Asilo" aprobado por el Consejo de la Unión Europea. Este Pacto sienta las bases para la elaboración del próximo plan quinquenal que sustituirá al Programa de Ámsterdam (2004-2009). Las líneas básicas de este documento son: a) La organización de la inmigración legal a partir de las necesidades del mercado y de los Estados miembro; b) combatir la inmigración irregular y expulsar a quien se encuentre en situación de irregularidad; c) reforzar el control de las fronteras incluso más allá de los límites territoriales de la Unión; d) armonizar (por no decir, vaciar) el régimen de asilo, y e) fomentar la cooperación con los paises de origen y tránsito en materia de control, readmisión y contratación de migrantes a cambio de inversiones y desarrollo. No es necesario un análisis en profundidad de unas premisas tan reveladoras sobre cuál va a ser el rumbo de las políticas migratorias en los años venideros.

Por lo tanto, si bien la Unión Europea, como la conjunción de varios Estados independientes incluidos dentro de una comunidad política más amplia, debe calificarse como un ente supranacional, el carácter transnacional lo aportan las relaciones estables y transfronterizas llevadas a cabo por los múltiples agentes policiales, administrativos y económicos que son quienes finalmente implementan las políticas económicas y de control. Es necesario decir que se trata de una transnacionalización de carácter vertical. Dicho de otro modo, "desde arriba", fruto de la implementación de las normas emanadas por las instituciones comunitarias, en los países miembros y también trascendiendo las fronteras exteriores, como hemos visto. ¿Cuáles son las consecuencias sociales de ese modelo de transnacionalización del control neoliberal? ¿Existe una respuesta por parte de la sociedad civil? ¿En qué términos y con qué objetivos?

En este texto, se pretende realizar una aproximación a la transnacionalización de la lucha por los derechos de los inmigrantes, precisamente en contra de ese Estado transnacional de vigilancia. Para ello, tras describir en la introducción la actitud adoptada por la UE de constituirse en un verdadero Estado transnacional de vigilancia para controlar los flujos migratorios, en las siguientes secciones 
haremos referencia a un fenómeno calificable como las redes transnacionales por los derechos de los migrantes. Se trata de la conjunción virtual y real de un conjunto de organizaciones dispersas territorialmente pero que convergen en dos puntos decisivos. El primero es Internet como herramienta imprescindible para la coordinación, el debate y la toma de decisiones. Y el segundo son los múltiples encuentros que sirven tanto para realizar acciones reivindicativas y protestas como para reorganizar la lucha. Las dos últimas secciones tienen como objetivo prestar atención a un conjunto de acciones desarrolladas por organizaciones, localizadas en distintos contextos urbanos, pero enmarcadas en el espacio transnacional. Para ello, se han empleado fuentes como las webs de organizaciones y redes transnacionales, periódicos y boletines especializados en contra-información así como comunicados de convocatorias y manifiestos emitidos con ocasión de eventos y actos de protesta. Esto nos ha permitido aproximarnos al funcionamiento, a las múltiples herramientas empleadas así como a los planteamientos de este nuevo agente, las redes transnacionales por los derechos de los migrantes.

\section{LA RESISTENCIA DESDE ABAJO: LA RED tRasNacional COMO NUEVO MECANISMO DE LUCHA POR LOS DERECHOS}

A pesar del importante reforzamiento selectivo de las fronteras incluso más allá de éstas, la transnacionalización no es una estrategia única de los organismos supranacionales o de las corporaciones empresariales. Ni mucho menos. Desde el momento que es causa y efecto de los procesos de globalización también encuentra su desarrollo en la sociedad. Los contactos transfronterizos son producto de los desarrollos tecnológicos y de las comunicaciones, desplegados por múltiples agentes a través de actividades transnacionales de colectivos activistas o de comunidades migrantes. Precisamente, de la confluencia de estos dos fenómenos surge lo que denominaremos "redes transnacionales por los derechos de los inmigrantes", es decir, aquellos contactos, estrategias y acciones tejidas a través de las fronteras con el objetivo de resistir a las consecuencias negativas (exclusión, detenciones, expulsiones, muertes...) de las políticas de control de la inmigración desarrolladas por los paises del Norte, concretamente la UE, EE.UU. o Australia7. No obstante, a pesar de la delimitación conceptual a priori de estas redes, tal vez sea necesario situarlas en un debate teórico. Para ello, vamos a presentar tres perspectivas complementarias de aproximación al caso que nos ocupa: Por una parte, el transnacionalismo político y las prácticas transfronterizas surgidas en el seno de las comunidades inmigrantes; en segundo lugar, los movimientos sociales por la justicia global; y en tercer lugar, como complemento a las dos anteriores, la legalidad cosmopolita subalterna.

Hoy en día, los lazos sociales transfronterizos, como han señalado Basch, Glick Schiller y Blanc-Szanton (1994)8, Smith y Guarnizo (1998), Massey et al. (1999), Portes et al. (1999), o Vertovec y Cohen (1999), constituyen importantes mecanismos de migración y de satisfacción de las necesidades económicas, informativas y afectivas en los procesos de salida, viaje y asentamiento. Dice Castles que "la migración transfronteriza es un proceso social dinámico, que resulta muy difícil de detener una vez iniciado. Lo impulsan las redes sociales que los inmigrantes desarrollan como forma de sobrellevar y de humanizar la experiencia de la migración" $(2003,23)$. El desarrollo de sistemas de interconexión entre distintos lugares del planeta ha propiciado, además, la creación de espacios de participación que transcienden los territorios estado-nacionales. El transnacionalismo político, en un sentido amplio (Baubock, 2003), es decir, derecho al voto en origen, lobby político tanto destino-origen como origen-destino constituye una de las principales formas de trascender las fronteras físicas que delimitan el territorio y las fronteras jurídicas que son marcadas por la ciudadanía nacional. Diversos estudios llevados a cabo tanto desde Estados Unidos (Portes et al., 2009) como desde Europa (Østergaard-Nielsen, 2001, 2003), muestran que las prácticas políticas transnacionales van, poco a poco, creando un espacio continuo y simultáneo de intersección de adscripciones jurídicas y lealtades políticas, con trascendencia tanto en origen como en destino.

No obstante, el hecho de que estos estudios mantengan la noción de "origen-destino" como elemento fundamental del transnacionalismo de carácter político (y también cultural, social, económico o jurídico), limita el campo de análisis que nos ocupa en el sentido de que excluye aquellas prácticas que ni parten ni tienen como destino el país originario. Tomemos como ejemplo los "tipos ideales" que considera Østergaard-Nielsen en su estudio sobre prácticas

ARBOR CLXXXVI 744 julio-agosto [2010] 689-703 ISSN: 0210-1963 
políticas trasnacionales desarrolladas por inmigrantes. Para esta autora, la actividad política trasnacional es aquélla en la que tanto inmigrantes como refugiados se ven envueltos con el origen $(2001,762,763)$. Primeramente, refiere a aquellas prácticas que tienen como objetivo mejorar su situación en los países de recepción o residencia, es decir, obtener mejoras en cuanto a derechos políticos, civiles, económicos o sociales. Esto sucede cuando el gobierno del Estado de origen intercede por sus ciudadanos o sus descendientes ante los gobiernos en los que éstos residen. Asimismo, en segundo lugar, los inmigrantes y refugiados también desarrollan acciones referidas a incidir, ya sea en apoyo u oposición, a la política interior y exterior del gobierno de origen. Es en este contexto en el que se enmarcan las exigencias de reconocimiento de un status de representación institucional especial de aquellas personas residentes en el extranjero. En tercer lugar, lo que denomina "acciones políticas translocales" representa aquellas iniciativas procedentes de la sociedad de destino y que buscan mejorar la situación de las comunidades locales de origen. Finalmente, las diásporas juegan un papel importante en la participación transnacional en el sentido de que tejen unos vínculos, incluidos los políticos, entre distintos Estados, pero sin perder nunca el referente del origen, a pesar de que éste ya no exista como organización políticainstitucional o les niegue legalmente la participación. En definitiva, a partir de estos cuatro tipos de participación transnacional observamos que el papel del "origen" es fundamental para el análisis del transnacionalismo político. ¿Cómo se podría abordar el estudio de aquellas prácticas en que, siendo desarrolladas por inmigrantes, no influye necesariamente el destino-origen, sino que transcurren en otro espacio transnacional?

Esta carencia puede verse cubierta si nos aproximamos a los "movimientos sociales transnacionales" (Juris, 2006; Starr, 2005; Evans, 2000, 2007; Keck y Sikkink, 1998), entendidos éstos como "redes supranacionales de actores que definen sus causas como globales y que organizan campañas de protesta que implican a más de un Estado" (Della Porta et al., 2006, 18). La necesidad de transnacionalización de las luchas está precisamente determinada por el factor también transnacionalizado del adversario, ya sean las empresas multinacionales, las instituciones globales (la OMC, el FMI, el BM, entre otras muchas) o sus políticas neoliberales (los Tratados de Libre comercio, el Acuerdo Multilateral de Inversiones, etc.). Como dicen
Cohen y Shirin, "las necesidades de la era global requieren respuestas globales" $(2004,28)$. Se trata de la confluencia heterogénea de movimientos sociales preocupados por cómo solucionar los problemas que les afectan a nivel local, pero conscientes de que es el espacio transnacional sobre el que deben operar para hacer posibles las mejoras locales. Es "un movimiento de movimientos" (Hardt y Negri, 2004, 116).

Una primera característica de estos movimientos es la coordinación informática. La posibilidad de distribuir información por Internet a través de las fronteras permite articular una "política de escala" basada en la coordinación y comunicación directa entre unidades autónomas a pequeña escala, sin necesidad de estructuras rígidas y jerárquicas intermediarias como los partidos políticos o los sindicatos. Asimismo, la simultaneidad es otra facilidad aprovechada por estos movimientos. A pesar de la brecha digital aún existente, la posibilidad de difundir de manera masiva una información y a tiempo real es una herramienta que ha penetrado en el activismo, transformándolo radicalmente. Además de Independent Media Centers ${ }^{9}$, existen millones de sitios web permanentes o temporales destinados a suministrar información, recursos, difundir manifiestos, etc. El papel de las listas de contactos o de distribución es el de enviar comunicados y llamamientos a la acción, comentarios, permanecer informados sobre las actividades y para realizar tareas logísticas concretas, mientras que la planificación más compleja, el debate político y la construcción de relaciones tienen lugar durantes los encuentros físicos (foros sociales, manifestaciones u otro tipo de eventos), en los que toman cuerpo las redes virtuales.

La transnacionalidad-globalidad es otra característica, que no solamente se basa en la práctica de contactos y relaciones transfronterizas sino también en la autodefinición de red o movimiento transnacional a través de signos, discursos, imágenes y tácticas. La percepción de la necesidad de coordinarse trascendiendo las fronteras ha conllevado a que la misma transnacionalización sea percibida como un fin intermedio en sí mismo. Ello viene marcado evidentemente por el carácter global de campañas como la abolición de la deuda externa, la lucha contra el cambio climático o las mismas políticas de control de la inmigración de la Unión Europea, como se verá más adelante. Además, la materialización de convocatorias, encuentros y actos de protesta a nivel supraestatal requiere de un sistema 
transnacionalizado donde los distintos agentes localizados en puntos distantes puedan tomar parte en los procesos de planteamiento, debate y toma de decisión.

Precisamente, este sistema transnacionalizado y virtual permite la descentralización democrática, es decir, la formación de un proceso horizontal de democracia directa, que implica una coordinación entre grupos, con objetivos y demandas comunes pero sin alterar su estructura interna. Como dicen Hardt y Negri, "la plena expresión de la autonomía y la diferencia de cada uno coincide con la poderosa articulación de todos" $(2004,116)$. Este aspecto es relevante en el sentido que rompe con una tradición de representación ya sea a través de partidos políticos 0 sindicatos. Frente a los mecanismos tradicionales de participación basados en estructuras centralizadas y verticales, el modelo alternativo es la coordinación informal o flexible entre grupos autónomos dentro de una estructura mínima que supone las asambleas periódicas, comisiones logísticas para unas tareas concretas, como son las finanzas o la comunicación con los medios. Esta informalidad se manifiesta, además de en la estructura organizativa, también en la praxis política, ya sea en la nueva concepción de manifestación con la incorporación de música, espectáculos circenses y teatrales reivindicativos o llamativas acciones simbólicas. Esta heterogeneidad práctica está fundamentada básicamente en la diversidad ideológica, cultural o lingüistica de los movimientos que componen la "multitud" y, por tanto, es una forma factible de aglutinar las múltiples luchas en torno a metas comunes sin que se vea comprometida la particularidad ni la autonomía del colectivo concreto.

Precisamente, frente una globalización económica basada en la dominación ideológica, la desigualdad social y la homogenización cultural, el fin último es la creación de un orden-sistema jurídico político alternativo basado en la justicia global. En vez de reconocer la "inevitabilidad del proceso de globalización económica", estos movimientos, defienden que "el crecimiento de las conexiones transnacionales puede ser potencialmente controlado para establecer una distribución más equitativa de la riqueza y del poder, creándose comunidades más sostenibles social y ecológicamente" (Evans, 2007, 495).

Esta contextualización teórica a la que nos hemos referido, se complementa también con lo que Boaventura de Sousa
Santos ha denominado la "Sociología de las emergencias" (Santos, 2005) y, concretamente, "la legalidad cosmopolita subalterna" (Santos, 1995, 2009; Santos y Rodríguez, 2007). Esta perspectiva socio-jurídica consiste en

"interpretar de una manera expansiva las iniciativas, movimientos y organizaciones que se resisten a la globalización neoliberal y exclusión social y que les ofrecen alternativas. Los rasgos de las luchas se amplifican y elaboran de una manera que hace visible y creible el potencial que se halla implícito o escondido en las acciones contrahegemónicas concretas" (Santos, 2009, 574).

Una propuesta en esta línea reivindica una concepción del ámbito jurídico más adecuada a reconectar Derecho y Política con el fin de generar instituciones jurídicas emergidas desde los cimientos sociales que irrumpen en los círculos de poder y decisión. Semejante tarea requiere, primeramente, la combinación de estrategias legales, ilegales y alegales mediante las cuales obtener los fines; segundo, busca la ampliación del canon jurídico ${ }^{10}$, más allá de los derechos individuales y la idea de autonomía de la persona, sin duda imprescindibles, hacia "concepciones solidarias de titularidad de los derechos, cimentadas en formas alternativas de conocimiento jurídico"; finalmente, un contexto como el contemporáneo donde los límites espacio-temporales desafian las concepciones tradicionales, requiere operar simultáneamente a distintas escalas a través de los instrumentos jurídicos y políticos que cada una proporciona. En definitiva, se trata de emplear el Derecho (los derechos individuales y colectivos) en un sentido emancipatorio.

Esta aportación teórica nos ha ofrecido unas bases mínimas para analizar el fenómeno de las redes transnacionales por los derechos de los inmigrantes. En la siguiente sección nos vamos concentrar en unas acciones concretas con el objetivo de "amplificar" su contenido, reivindicaciones y dinámicas.

\section{Aproximación a las redes de acción TRANSNACIONAL POR LOS DERECHOS DE LOS INMIGRANTES}

La necesidad de "actuar global para cambiar lo local" ha derivado en el encuentro virtual y físico de sinergias que 
actuaban individualmente en distintos lugares del planeta en contra de las políticas de control y criminalización de las migraciones. Tres de estas redes, No border, Frassanito y Migreurop (aunque existen otras más), servirán de ilustración para definir la naturaleza de estas formas emergentes de participación transnacional.

La red No border nace en 1999 de la convergencia de campañas, en distintos países europeos, en el momento en el que los extranjeros indocumentados comienzan a organizarse y a visibilizarse a través de ocupaciones, especialmente de iglesias, convirtiéndose en un movimiento autónomo. Hasta 2004, año de cese de sus actividades, más de 9 organizaciones de distintos países de Europa han trabajado conjuntamente creando nuevas formas de colaboración y resistencia contra lo que denominan "toda forma de explotación y división" como plataforma de intercambio de información y experiencia entre grupos e individuos involucrados en luchas anticapitalistas y con inmigrantes organizados. Su actividad se ha centrado en 5 ejes: La lucha contra las deportaciones, la organización de los no boder camps ${ }^{11}$ y la cooperación en los Días transnacionales de acción por los derechos de los inmigrantes, sobre los que se volverá más adelante, campañas contra la gestión global de las migraciones por entidades de gobernanza neoliberal (por ejemplo, la Organización Mundial de las Migraciones), y la lucha contra los centros de internamiento para extranjeros.

La red Frassanito ${ }^{12}$, en su propio ideario, se define como una red transnacional compuesta por colectivos que trabajan en Europa, en torno a movimientos y luchas de inmigración, aunque han sido conscientes de la necesidad de expandir sus acciones más allá de las fronteras europeas. El boletín transnacional "Crossing borders" es un claro ejemplo ${ }^{13}$. Como veremos en la siguiente sección, la red Frassanito ha sido una de las redes más activas en la organización y apoyo a acciones como los Días transnacionales de acción por los derechos de los inmigrantes.

La red Migreurop surgió en el Foro Social de Florencia en el año 2002, constituyéndose como red europea de militantes e investigadores "cuyo objetivo es dar a conocer la generalización del encierro de los extranjeros desprovistos de título de estancia y la multiplicación de los campos, dispositivo que fundamenta la política migratoria" (Presentación de Migreurop, 2003). Durante 3 años ha trabajado de manera informal realizando encuentros, como el organizado en el Parlamento Europeo en febrero y junio de 2003, configurando un mapa de la "Europa de los campos"14 en julio de 2004 o las jornadas sobre "Externalización de extranjeros en Europa" celebradas en Sevilla en junio también de 2004. En noviembre de 2005, tras una asamblea que tuvo lugar en París, organizaciones de Bélgica, Gran Bretaña, Italia, Marruecos, Francia y España constituyeron formalmente la Red Migreurop mediante la discusión (y posterior aprobación en febrero del 2006) de unos estatutos y la constitución de un consejo de representación y administración formado por delegados de las organizaciones y personas individuales que participan en la red.

Estas redes no son más que un ejemplo de la creación de un espacio transnacional, donde tiene lugar el intercambio de información digital, se generan debates en cuanto al fondo y la forma de las acciones, etc. Sin embargo, todos estos procesos de discusión y deliberación virtual se manifiestan físicamente en los encuentros y en los eventos que tienen lugar en distintos espacios, así como con las convocatorias trasnacionales de "lucha" por los derechos de los inmigrantes, donde se generan nuevos objetivos y planes de actuación futura.

\section{LA PRAXIS LOCAL DE LA LUCHA TRANSNACIONAL}

Las prácticas transnacionales por los derechos de los inmigrantes se materializan en espacios concretos y simbólicos, ya sean ciudades, centros de internamiento, fronteras, etc. Ello responde a que estas prácticas no tienen lugar en un "tercer espacio imaginario" sino que "mientras que conectan colectividades situadas en más de un territorio nacional, están plasmadas en relaciones sociales específicas entre personas específicas, situadas en localidades inequívocas, en tiempos determinados históricamente" (Smith y Guarnizo, 1998, 11). En este apartado nos referiremos, precisamente, a esas localizaciones de las luchas generadas a partir de las reflexiones y deliberaciones surgidas en red. Concretamente, desde los encierros de 2001, en los que un millar de inmigrantes sinpapeles tomaron una decena de iglesias en demanda de derechos fundamentales y la regularización, se ha generado en Barcelona un importante movimiento de resistencia, ya sea a 
través de organizaciones, de movimientos autónomos y sindicatos, pero fundamentalmente a través de colectivos como los sinpapeles (Papers per a Tothom, la Assemblea per la Regularització Sense Condicions -ARSC-, etc.), contra las fronteras (Espai per a la Desobediència a les Fronteres, Cornellá sense Fronteres), etc. Por eso mismo, se prestará atención especial a las acciones que han ido teniendo lugar en este espacio urbano concreto. No se trata de hacer un inventario exhaustivo sino de reseñar unos ejemplos que ilustren cómo una iniciativa transnacional se sustancia en lo local. Para ello, nos vamos a referir a los Días transnacionales de acción por los derechos de los inmigrantes, las caravanas europeas contra las fronteras y por la libertad de circulación, los MayDay y la Cadena Transnacional de Acciones relacionadas con la Migración.

\section{Los Días transnacionales}

El 31 de enero de 2004, cerca de cuatro mil personas de múltiples procedencias recorrieron el centro de Barcelona. El hecho de que las pancartas estuvieran escritas en más de 10 idiomas (catalán, español, inglés, francés, árabe, amazigh, urdu, bengalí, etc.) reflejaba la diversidad de los participantes. Muchos de ellos eran inmigrantes sin papeles, que se manifestaron para pedir la regularización sin condiciones, el cierre de los centros de internamiento, el fin de las deportaciones o los derechos fundamentales como reunión, asociación o huelga, etc. Durante la manifestación, se recuperaron lemas que fueron habituales durante los encierros en las iglesias de 2001, como "Papeles para todos" o "We want papers". Al mismo tiempo, se coreaban también consignas contra el Forum de las Culturas 2004 como símbolo de la institucionalización de la especulación global. Además de la gran manifestación, fruto del contacto de las múltiples organizaciones sociales, sindicatos y partidos políticos extra-parlamentarios, se constituyó ARSC, movimiento fundamental en las luchas comprometidas con la defensa de los derechos de los inmigrantes en los últimos años.

Simultáneamente tuvieron lugar cientos de acciones organizadas en más de 40 ciudades europeas como Frankfurt, Londres, Viena, Madrid, Barcelona, Calais, Lille, Marsella, Lisboa, Berna, Ginebra, etc. En París, por ejemplo, más de 100 sinpapeles y grupos de apoyo ocuparon pacíficamente la sala de plenos del Consejo económico y social, con el fin de reunirse con los sindicatos y asociaciones firmantes de un informe que denunciaba la situación de persecución de los sinpapeles en Europa. Tras el debate con el Vicepresidente del consejo y los representantes de la CGT y otras organizaciones, se obtuvo como resultado un compromiso para poder celebrar unas reuniones conjuntas entre las organizaciones del Consejo y los protestantes para cooperar entre sindicatos y organizaciones en contra de la propuesta capitalista de crear una clase global de pobres y excluidos. Fue el primer Día europeo de acción por los derechos de los migrantes.

Este Día de acción fue convocado a través de un manifiesto difundido masivamente por las webs de colectivos y listas de distribución. Era el "Manifiesto europeo hacia una convergencia y una unión de las luchas de los sin papeles, los refugiados y los inmigrantes en Europa". Este documento fue acordado por varios colectivos europeos de personas sinpapeles, refugiados e inmigrantes a través de una serie de reuniones celebradas en el Campo de NoBorder en Estrasburgo, en julio de 2002; en Leiden (Peoples Global Action), Berlín (la gira de Caravana), Bruselas, Florencia (Foro Social 2002), Londres (Foro Social 2003) y, finalmente, en Saint Denis (Paris) por las organizaciones asistentes al Foro Social Europeo en 2003.

La propuesta principal del manifiesto es la formación de "una red que cruce las fronteras nacionales" con el objetivo de "crear una fuerza mutuamente responsable, autónoma y colectiva, dirigida por I@smism@s protagonistas, y capaz de responder a los ataques económicos y políticos que van en aumento en Europa promovidos por los mismos gobiernos". Lo firman más de una veintena de organizaciones de 7 países europeos, entre los que destacan Tavolo Migranti del Social Forum Italiani, la Coordination Nationale des Sans Papiers de Francia o Papers per a Tothom de Barcelona.

El segundo Día europeo de acción por los derechos de los migrantes tuvo lugar el 2 de abril de 2005 y planteó como principal reivindicación la libertad de movimiento y el derecho de permanencia "como alternativa al proceso constitucional europeo", representado éste por los centros de retención más allá de las fronteras externas (Balcanes, Libia, Marruecos...), el modelo de ciudadanía europea excluyente y de jerarquización de derechos, y el nuevo modelo de gestión de mano de obra basado en la precarización y la explotación.

ARBOR CLXXXVI 744 julio-agosto [2010] 689-703 ISSN: 0210-1963

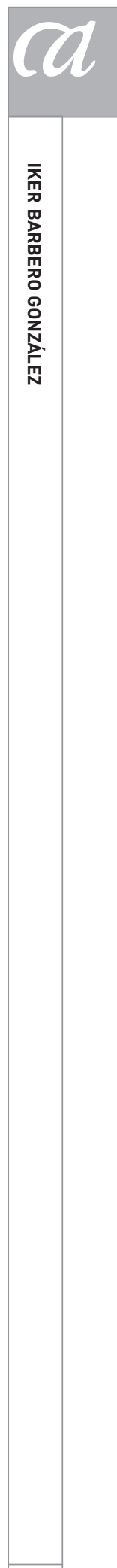

695 
En este caso, el llamamiento a las manifestaciones, acciones y luchas en toda Europea para "promover un marco transnacional" adquirió una dimensión mayor que el año anterior. En primer lugar por la capacidad de convocar a un número mayor de adhesiones, casi una centena de organizaciones provenientes de 12 paises europeos. Este hecho, además de reflejar el aumento de la capacidad de difusión de la convocatoria, también pone de manifiesto la voluntad de la transnacionalización de las luchas. En segundo lugar, secundaron la llamada dos redes de carácter propiamente transnacional: Frassanito y Euromarches/Marches europeennes. $Y$, en tercer lugar, al vincular esta convocatoria con otra de carácter también transnacional EuroMayDay (1 de mayo de 2005), se creó una conexión entre distintos momentos para aprovechar sinergias y construir lazos entre acciones.

La cita fue secundada por toda Europa e incluso en EE.UU. En Italia, activistas sociales ocuparon sedes de compañías aéreas involucradas en las deportaciones y bloquearon los accesos a varios centros de detención de inmigrantes, así como concentraciones ante sedes de ONGs que llevan a cabo su labor en centros de identificación y permanencia temporal para inmigrantes. En Rótterdam, 200 personas lograron bloquear dos barcos en los que se encontraban recluidos unos 800 inmigrantes. En San Diego (California), un centenar de personas protagonizaron una marcha hacia la valla que marca la frontera con México. En la región de Brandenburgo (Alemania) la manifestación, compuesta principalmente por refugiados autoorganizados, logró penetrar en un campo de refugiados, a pesar de los grandes obstáculos de seguridad. En Almería, más de 2.000 inmigrantes, en su mayoría subsaharianos, reclamaron entre otros derechos un empadronamiento y vivienda digna. En Barcelona, la manifestación convocada por la ARSC a las 6 de la tarde, desde Plaza de la Universidad hasta la Delegación del Gobierno, fue secundada por 3.500 personas. Además, este día de lucha coincidió temporalmente con el proceso de regularización abierto a raíz del nuevo Reglamento de extranjería 2393/2004. Ante las condiciones excesivas y utilitaristas requeridas para la regularización (entre otras exigencias, era el empresario quien debía presentar la proposición de contrato de trabajo, quedando el inmigrante subordinado a la voluntad del mismo), las asambleas de inmigrantes de Cornellá, Santa Coloma y Barcelona capital, acordaron realizar un encierro en locales sociales, religiosos y universitarios, y con carácter indefi- nido. Este llamamiento fue secundado por 700 personas, principalmente pakistanies, hindis, bangladeshis, marroquies, búlgaros y latinoamericanos, algunos de los cuales mantuvieron incluso una huelga de hambre.

El tercer Día de acción por los derechos de los migrantes fue convocado para el 7 de octubre de 2006, marcado de manera contundente por los episodios de la valla de Ceuta y Melilla y las acciones posteriores ${ }^{15}$. El Ilamamiento fue aprobado en la Asamblea final del Foro Social de Atenas, donde la cuestión migratoria se consagró como un eje temático especifico y se decidió dar un paso más y coordinar acciones por toda Europa para el 7 de octubre de 2006. Posteriormente también fue ratificado por la Asamblea de Movimientos Sociales en el Foro Social Mundial de las Migraciones (Rivas, Madrid).

El comunicado comienza con una frase del Foro Social Policéntrico de Bamako/Malí celebrado en enero de 2006: "Con la excusa de combatir la inmigración clandestina, los gobiernos están adoptando políticas represivas y expanden cada vez más las fronteras de las naciones enriquecidas mediante centros de detención, desalojos, expulsiones, y selección de la mano de obra". El objetivo de esta cita es poner de manifiesto la firme repulsa al régimen migratorio europeo basado en la externalización de las fronteras, las vallas, los disparos mortales, las deportaciones masivas al desierto. Por otra parte, es una llamada a socavar dicho régimen mediante luchas desde todas las fronteras: las externas (al otro lado de la valla) y las internas (contra centros de internamiento y las deportaciones). En este sentido, un hecho relevante de esta convocatoria es la afirmación del carácter global de las migraciones, y por tanto de ahi surge la necesidad de conectar también con los movimientos de migrantes en el continente africano y americano a través de un día simultáneo de acción. "En el período entre el Foro de Bamako y el de Nairobi, proponemos una movilización internacional durante todo el año en defensa del derecho de todas las personas a circular libremente por el mundo y para determinar su propio destino... Finalmente convocamos a un día internacional de movilización que podría desarrollarse en los lugares/símbolos de las fronteras (aeropuertos, centros de detención, embajadas, etc.)". El que esté firmado por centenares de organizaciones de 21 países, no sólo europeas, sino también africanas (Níger, Senegal Mauritania, Marruecos Malí, Costa de Marfil Congo, Camerún o Benin), Canadá o Ucrania, las redes y 
por las organizaciones europeas Frassanito, Forum Civique Europee y Next generation, y que, además, cuente con la Adhesión de la Conferencia no gubernamental euroafricana en julio de 2006, es una evidencia del comienzo de alianzas entre el Norte y el Sur.

El carácter transnacional del manifiesto así como la disparidad de procedencia de los colectivos convocantes se vieron reflejados en actos y protestas que tuvieron lugar en más de 30 ciudades de Europa, África y EE.UU. En Ceuta, por ejemplo, se celebró un acto simbólico junto a la valla que limita con Marruecos, en conmemoración de las cinco personas que fueron abatidas el 29 de septiembre de 2005. En Moscú, un grupo de activistas, representando a refugiados, se congregaron junto al Ministerio de Interior portando máscaras médicas en la boca y ropajes manuscritos con historias de vida de refugiados, mientras que un grupo de samba y un ejército de clowns simulaban flagelar a los "refugiados" y repartían entre los asistentes y los viandantes el periódico Crosssing Borders. En Benin, los días 6, 7 y 8 de octubre se celebraron manifestaciones, una conferencia y una sesión religiosa en el marco del día de acción. A pesar de la coincidencia con el Ramadán, que limitó la presencia de musulmanes africanos y asiáticos, se reunieron algo más de 1.000 personas en la convocatoria de Barcelona. En declaraciones al periódico Diagonal, un miembro de la Federación Estatal de Asociaciones de Inmigrantes y Refugiados, al finalizar el Encuentro Estatal por los Derechos de los Inmigrantes, declaró: "Estas movilizaciones tienen dos niveles de lectura, el de las movilizaciones, que es público, pero además hay un esfuerzo por coordinarse, por trabajar juntos, entre las diferentes organizaciones de inmigrantes, y con las organizaciones solidarias, a nivel local, estatal y europeo. Es un trabajo invisible y lento, cuyos frutos se verán a medio plazo"16. Estaba surgiendo la Red Estatal por los Derechos de los Inmigrantes.

\section{Las Caravanas europeas}

La primera Caravana europea contra la valla, "ninguna persona es ilegal", tuvo lugar los días 4, 5 y 6 de noviembre de 2005, prácticamente un mes después de los trágicos episodios de las "vallas".

La rápida organización fue fruto del contacto transfronterizo a través de contactos reales así como virtuales: "Poco a poco la idea fue tomando forma y se pasó de reunio- nes presenciales en cada territorio, a una coordinación sustentada en Internet a escala estatal y europea (listas, wikis, chats, etc.). El proceso organizativo se desplegó en apenas veinte días, con un enorme esfuerzo colectivo que incluyó a personas de Europa y el norte de Marruecos. Creo que esta capacidad para modular diferentes redes y hacer frente a una situación de tal complejidad es una de las mayores virtudes de esta experiencia"17.

A la convocatoria estaban Ilamados "grupos y espacios sociales autoorganizados, comunicadores sociales, ciudadanos europeos nacidos aquí y allá, asociaciones de vecinos, asambleas y foros de inmigrantes". Quinientas personas procedentes de todo el Estado español así como de Suecia, Francia, Alemania e Italia se dirigieron "hacia las vallas como lugar de un crimen perpetrado en nombre de las democracias europeas".

Las demandas eran claras: a) Regularización inmediata de los inmigrantes que se encontraban en Ceuta y MeliIla; b) Investigación independiente y rápida de los hechos ocurridos en la frontera y juicio a los responsables de las muertes en la valla y en el desierto; c) Retirada inmediata del Ejército de la frontera porque su utilización frente a la población civil era absolutamente ilegal; d) Paralización de la política migratoria de la Unión Europea basada en la externalización de las fronteras, y, por tanto, del proceso de creación de centros de internamiento en los países de tránsito y de la repatriación de migrantes a paises terceros; d) Resolución favorable de todas las demandas de asilo político solicitadas desde que se desencadenaron las primeras muertes en Ceuta y Melilla.

Finalmente, tras el intercambio de experiencias con los inmigrantes africanos "internados" en el Centro de Estancia Temporal para Inmigrantes y una reunión con la Delegación del Gobierno de Ceuta, en la que se trasmitieron las demandas de resolver favorablemente las peticiones de asilo, así como una investigación independiente sobre las muertes de la frontera, finalizaba la experiencia, pero comenzaba una inercia.

Si la primera Caravana que tuvo lugar en Ceuta, expresaba el rechazo a la política europea de fronteras exteriores y a la nueva tendencia de externalización del control a los países limitrofes, ahora, con la segunda edición, los días 23,24 y 25 de junio de 2006, lo que se pretendía expresar

ARBOR CLXXXVI 744 julio-agosto [2010] 689-703 ISSN: 0210-1963

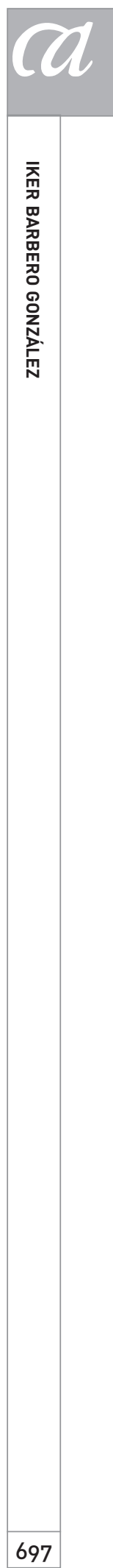


era la repulsa a las fronteras construidas en el interior de los países y en las ciudades para controlar, detener y expulsar a los inmigrantes que logran entrar en Europa sin permiso. Así, la segunda Caravana europea por la libertad de movimiento tuvo lugar en la ciudad de Barcelona, principalmente, por dos motivos: la aprobación de una polémica ordenanza municipal que criminalizaba aspectos de la vida cotidiana de los inmigrantes ${ }^{18}$, y porque se inauguró el Centro de Internamiento de Extranjeros (CIE) en la Zona Franca, en sustitución del anterior de La Verneda, objeto de reiteradas denuncias por parte de organizaciones locales e instituciones internacionales de defensa de los derechos humanos.

La Caravana de Barcelona fue difundida en distintas convocatorias europeas como las Jornadas Europeas sobre Inmigración, Ciudadanía y Globalización en Terrassa, el Mayday de París, el Foro Social Europeo en Atenas o la inauguración del Sindicato Invisibles Workers of the World (IWW) en Italia.

Aunque el acto principal estaba previsto que fuera una manifestación que recorriera la ciudad, la atención mediática se dirigió hacia una acción de "desmontaje simbólico" del $\mathrm{CIE}$, inspirada en otras anteriores ya realizadas en Italia u Holanda. En el "desmontaje" participaron más de 100 personas, y concluyó con la detención y procesamiento de 59 personas, incluidos dos abogados en ejercicio y dos periodistas. Las muestras de solidaridad con los detenidos llegaron por medio de varias manifestaciones frente a la comisaría de La Verneda donde estaban los detenidos y junto a los juzgados, así como mediante comunicados provenientes de todo el Estado y distintos lugares de Europa, como el sindicato IWW, la red Frassanito, la Area condivisa della disobbedienza sociale. Durante estas jornadas, además, tuvo lugar la experiencia Fada'iat, un proyecto muy extenso de arte, arquitectura y tecnología en la frontera, en torno a la libertad de movimiento y la libertad del conocimiento (www.fadaiat.net).

\section{Los EuroMayDay}

Los EuroMayDay, como su propio nombre indica, se celebran el 1 de mayo, Día Internacional del Trabajo. Aunque inicialmente surgió en 2001 en Milán (ciudad donde siguen teniendo lugar multitudinarias manifestaciones), gracias a Internet y otros medios, se han expandido por diversas ciu- dades de Europa como días de acción política promovidos por redes de activistas anti-capitalistas, feministas y colectivos de inmigrantes contra la precariedad a la que conduce el modelo económico neoliberal europeo. En 2005, la red EuroMayDay empleó el slogan Precarious people of the world let's unite(conspire) and strike 4 a free, open, radical Europe (precarios del mundo, unámonos -conspiremos-y peleemos por una Europa libre, abierta y radical). Como un activista de Barcelona la define, "la MayDay trata de producir un dispositivo que entrecruce los movimientos antisistémicos más potentes de los últimos años en Europa: los centros sociales, el movimiento global expresado en las contracumbres, el mediactivismo, el ecologismo urbano y las street parade (reclaim the streets, critical mass) o las luchas por la ciudadanía universal y por la libertad de movimiento (tanto de los sinpapeles -en encierros, huelgas de inmigrantes $u$ otras movilizaciones- como de los europeos de origen -border camps, movilizaciones contra los CIE)" (Arbide, 2005).

Concretamente, el papel de la lucha por los derechos de los inmigrantes, como un colectivo más al que se somete a la precariedad (trabajos peor remunerados, economía sumergida sin contrato y, por tanto, sin derechos), ha estado presente en los EuroMayday. En los últimos años, se ha retomado la celebración del 1 de mayo en EE.UU., gracias principalmente a las marchas convocadas por organizaciones de inmigrantes, en su mayoria latinas, pero también asiáticas y afroamericanas. Este día, declarado "un día sin inmigrantes", en ciudades como Washington, Los Ángeles, Nueva York o Chicago, a través de las denominadas "megamarchas" (millones de manifestantes) se está reclamando la eliminación de políticas de criminalización (como la Pratioct Act o la propuesta Ley HR 4437 -Ley para el control de la inmigración, el antiterrorismo y la protección de las fronteras de 2005-).

En las distintas convocatorias que han tenido lugar en Barcelona (MayDay Barcelona 2004, EuroMayDay BCN 2005, Mayday Sur 2005, 2006 y 2007) y recientemente en Terrasa (2008 y 2009), los colectivos de inmigrantes han denunciado, además de la dificultad para encontrar viviendas dignas en un contexto de especulación urbanística, la situación de exclusión laboral y social. Como dice un comunicado de la ARSC para el MayDay de 2004, "hay muchos problemas comunes, pero los inmigrantes tienen, cada vez más, uno específico que no se puede obviar: los papeles. El gobierno español con su política de extranjería pretende crear entre 
la población civil un sentimiento de miedo, de sospecha, de rechazo, de racismo que distraiga las verdaderas razones de las injusticias cotidianas". Por eso mismo, la manifestación de 2004, que fue convocada por múltiples colectivos ${ }^{19}$ y que congregó a más de 10.000 personas, estuvo encabezada por un millar de sinpapeles y la demanda incondicional en este tipo de eventos, "papeles para todos". Esto, que implica la posibilidad de acceder a un trabajo digno, supone en última instancia una demanda de libertad de circulación. En definitiva, el derecho a una ciudadanía universal. Esta exigencia se repitió en la convocatoria de 2005, donde un similar número de personas, de nuevo, se sumaron a la consigna conjunta con otras ciudades europeas como Milán, evidentemente, pero también Sevilla, Ámsterdam, Copenhagen, Hamburgo, Helsinki, Londres, París, Estocolmo o Viena, entre otras. Así año tras año.

\section{La Cadena Transnacional de Acciones relacionadas con la Migración}

En 2008, y bajo el lema "!Combatiendo el régimen de fronteras! ¡Transnacionalización ya!" (Figthing the Border regime. Transnationalization now), se hacia un Ilamamiento común a la Cadena Transnacional de Acciones relacionadas con la Migración que tenía como objetivo realizar distintas acciones en ciudades europeas y de más allá de las fronteras exteriores. Tomando como referencia los Días de acción por la libertad de movimiento de 2004, 2005 y 2006 pretende convertir un espacio trasnacional a partir de las luchas cotidianas que suceden en los distintos lugares de Europa, así como en otros lugares más allá de las fronteras como Marruecos o Ucrania. "La cadena transnacional de acciones es un paso más hacia la vinculación de las luchas, un intento de construir comunicación y organización transfronteriza, sabiendo que las demandas de libertad de movimiento y el derecho a permanecer apuntan directamente al 'corazón de la bestia', contra el que los migrantes están luchando cada día y en todo lugar" (Manifiesto Figthing the Border regime. Transnationalization now).

La cadena de acciones realizó, durante ocho meses, múltiples "paradas" en ciudades europeas y africanas (Ámsterdam, Sevilla, Atenas, Londres, Milan, Turín, Bamako, Varsovia, Hamburgo y Malmö). En cada una de ellas, tenían lugar encuentros entre organizaciones locales y europeas, acciones de protesta urbana, como el EuroMayDay en Milán, ante instituciones fronterizas, como Frontex en Varsovia, y centros de investigación de las migraciones en Bamako. La cadena finalizó en el Foro Social Europeo en Malmö donde tuvo lugar el taller "Transnationalisation now!" Migration related Networking".

En el marco de esta cadena, la REDI convocó para el 23 de febrero una "Jornada Estatal por la Dignidad de las Personas Migrantes" basada en 12 propuestas (como, por ejemplo, una nueva regularización inmediata, garantías para la residencia y vida familiar, el cese de los abusos policiales y la discriminación, así como la igualdad plena de derechos). La jornada de lucha congregó a más de veinte mil personas en ciudades como Sevilla, Barcelona, Madrid, Iruña o Tenerife, así como otras muchas más. En la convocatoria de Sevilla, bajo el lema "Derecho social y laboral para todos. La inmigración no es un problema, el problema es la precariedad" se dieron cita casi 2.000 personas provenientes en autocares de toda Andalucía. En la capital catalana colectivos como Associació Papers i Drets per a Tothom, Espai per a la Desobediència a les Fronteras, Cornellà sense Fronteres, Federació dels Col.lectius Immigrants a Catalunya, CGT y muchos otros, se sumaron bajo el lema "Tenim dret a tenir drets. Ni exclusió ni discriminación". La composición de la marcha fue mayoritariamente de personas inmigrantes $y$, en especial, mujeres. Fue una marcha muy combativa a pesar de la intimidación generada por un despliegue policial de unas 30 furgonetas.

\section{UN MOVIMIENTO QUE CAMINA}

No cabe duda de que asistimos a un fenómeno aún incipiente, en formación y, por tanto, con sus limitaciones, sus deficiencias y sus contradicciones. Sin embargo, su potencialidad para contrarrestar el avance de un Estado transnacional de vigilancia es innegable. Cada vez surgen más iniciativas en lugares más distantes pero de manera coordinada y sincronizada. Las conexiones ya no son únicamente entre contextos europeos, sino que la unión entre organizaciones de África, Europa y América ha roto las distancias también entre el Norte y el Sur. Una verdadera transnacionalización de la lucha así lo requería.

La confluencia de sinergias entre múltiples colectivos convierte a las redes transnacionales en la vanguardia de las luchas por los derechos de los inmigrantes, tan limitados en

ARBOR CLXXXVI 744 julio-agosto [2010] 689-703 ISSN: 0210-1963

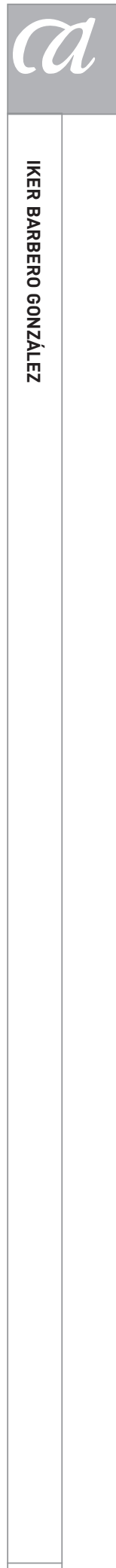

699 
los últimos tiempos. A pesar de suponer experiencias locales, el hecho de que se encuentren conectadas simultáneamente con otras muchas experiencias, las convierte en un "gran movimiento" capaz de intervenir en la agenda de grandes instituciones y de sus políticas. Aunque aún es pronto y existen muchas dificultades, se podria decir que se está forjando una nueva legalidad, cosmopolita y subalterna.
Con todo, a pesar de la deriva de las políticas de control (eufemísticamente llamadas de "gestión") y la regresión de los derechos y garantías de los inmigrantes, lo que nos indica que aún es largo el camino que falta por recorrer hasta llegar al Estado transnacional cosmopolita, asistimos a la formación de un movimiento flexible, capaz de adaptarse a los nuevos obstáculos para "desmontarlos".

\section{NOTAS}

1 El presente texto se enmarca en la investigación "Nueva ciudadanía y derechos de los inmigrantes" financiada por los Programas de Formación y Perfeccionamiento de Personal Investigador 2005-2009 (Departamento de Educación, Universidades e Investigación, Eusko Jaurlaritza).

2 Acrónimo de Terrorismo, Radicalismo, Extremismo, Violencia Internacional.

3 Balibar, en ¿Qué es una frontera? otorga un carácter heterogéneo a la frontera: "Bajo ningún concepto ciertas fronteras se hallan ya situadas en las fronteras en el sentido geográfico-político-administrativo del término, sino que residen en otro sitio, dondequiera que reejerzan controles selectivos" $(2005,84)$.

4 En esta misma línea, De Lucas establece una serie de categorías en virtud de la cual el Derecho "contra el enemigo" actúa en distintas instancias. Primeramente, un "enemigo exterior", es decir, aquella persona que deviene potencialmente emigrante irregular; el "enemigo a las puertas", para referirse a aquella persona que 0 bien se localiza en un puesto fronterizo exterior o bien en el interior pero aún controlado por la policía de fronteras (por ejemplo, un aeropuerto) y, finalmente, un nuevo tipo de "enemigo interno", el que viniendo de fuera consigue infiltrarse, consigue pasar la frontera para establecerse sin auto- rización en el territorio estatal (De Lucas, 2004).

5 El Consejo Europeo de Sevilla, de junio de 2002, centrándose principalmente en la inmigración irregular y en su combate efectivo, define claramente la nueva dirección hacia la que deben encaminarse las instituciones europeas: Lucha sin descanso contra la inmigración irregular, incluso en los países de origen. Para ello, además de incidir en una mayor gestión coordinada e integrada del sistema de fronteras exteriores, también Ilama a la celebración de acuerdos de readmisión y colaboración con terceros paises. A pesar de la voluntad de los gobiernos británico y español de recoger sanciones explícitas contra los Estados de origen que no colaborasen en la gestión-control de las migraciones, finalmente quedó bien como incentivos económicos o como una "amenaza" vinculada a los programas de desarrollo, según se interprete: "una colaboración insuficiente por parte de un país podría dificultar la intensificación de las relaciones de dicho país con la Unión"

6 Wihtol de Wenden se refiere a ellos como "la entrada principal y la puerta de servicio" (2000, 51-60). Mientras que la primera se abre para las élites económicas y trabajadores altamente cualificados, la puerta del servicio, permite entrar a "brazos" destinados a trabajar en sectores desregulados de la economía sumergida.
Aceptado: 10 de julio de 2009 
7 Sobre la formación de un "Gran muro del capital" que separa el Norte del Sur, ver el Davis (2008).

8 Estas autoras han proporcionado una definición ya clásica del transnacionalismo como "un proceso a través del cual los inmigrantes forjan y mantienen relaciones sociales multiescalares que vinculan sus sociedades de origen y las de asentamiento. Llamamos a estos procesos transnacionalismo para enfatizar que muchos inmigrantes hoy en día construyen campos sociales que cruzan fronteras geográficas, culturales y políticas" (Basch, Glick Schiller y Blanc-Szanton, 1994, 7).

9 Indymedia es un portal global, independiente, descentralizado (porque cuenta con cientos de subdivisiones por todo el mundo) y participativo, para periodistas y colectivos sociales que desean informar sobre cuestiones políticas y sociales. Surgió en 1999 durante las protestas contra la OMC en Seattle como mecanismo alternativo para la retrasmisión de la protesta (www.indymedia.org).

10 Ver Santos (2004), "Para la ampliación del canon democrático", en Democratizar la democracia: Los caminos de la democracia participativa, México, Fondo de Cultura Económica.

11 Los campamentos Noborder, son espacios físicos que sirven para el encuentro de activistas. El primer encuentro no boder camps tuvo lugar en Ámsterdam en diciembre de 1999, donde se estableció una lista de correo que permitió coordinar las acciones de muchas organizaciones (de dentro y fuera de Europa), intercambiando información y discutiendo sobre migraciones y fronteras. En los últimos años se han organizado diversos campamentos cerca de las fronteras de Europa en Polonia, Ucra- nia, Alemania, Sicilia, España, México o Grecia el más reciente. En el 2001 más de 1.000 personas participaron en el campamento cerca del aeropuerto de Frankfurt de donde partían numerosos vuelos charter que ejecutaban las expulsiones. Estos campos, además de cumplir el objetivo de actuar contra el régimen fronterizo, son también una oportunidad para establecer relaciones entre grupos distintos a través de debates y actividades culturales y festivas. En julio de 2002 el campamento se organizó con una presencia de 2.000 personas en Estrasburgo, donde se sitúa el Sistema de Información Shengen. Este campamento fue el escenario de varias manifestaciones, acciones y una plataforma de intercambio entre grupos, dando lugar al "Manifiesto por la convergencia de las luchas de los inmigrantes, refugiados y sin papeles de Europa", sobre el que se volverá más adelante. A partir de 2003, con el Freedon of Movement Tour, las experiencias de campamentos se multiplicaron celebrándose múltiples encuentros al año, diversificándose también los lugares.

12 Recibe el nombre de un lugar de Puglia (sur de Italia) donde tuvo lugar el No border camp 2003. Durante esta acampada se realizaron talleres y debates, así como acciones de protesta, entre las que destaca la protesta contra el CIE de Bari. Las sinergias generadas sirvieron como impulso para proseguir con el trabajo en red.

13 Se trata de un medio escrito y virtual que busca "potenciar la comunicación transnacional a partir del intercambio de información de experiencias y luchas contra el apartheid global del régimen migratorio y a favor de la libertad de movimiento y el derecho a permanecer". Está edi- tado en múltiples lenguas, publicado en Internet y distribuido por comunidades inmigrantes y organizaciones. Cada número ha coincidido con eventos transnacionales relacionados con el fenómeno de la inmigración y los espacios de reivindicación de derechos, como el Día transnacional de acción del 7 de octubre, el Foro social mundial de enero de 2007, celebrado en Nairobi, el 1 de mayo, Día Internacional del Trabajo. El objetivo es que cada número sea distribuido en los distintos actos realizados simultáneamente en cada país. El contenido del boletín va desde una cronología de las distintas acciones, manifestación o noticias relacionadas con los derechos de los inmigrantes hasta artículos temáticos como la regularización de las personas indocumentadas de Europa, las migraciones femeninas, la inmigración laboral o la realidad en las fronteras exteriores de Europa del Este y Sur.

14 Esta red se refiere a los "campos" no sólo aquellos lugares cerrados por "alambres de espino", sino también a los diversos dispositivos administrativos y obligaciones técnico-humanitarias destinadas a agrupar a los inmigrantes. En este sentido, la red ha venido trabajando en varios ejes: Recabar información sobre las politicas de campos y centros de internamiento que se localizan tanto dentro del territorio europeo como en los países limítrofes. Desmitificar la idea de campo como un lugar cerrado. Las nuevas acciones institucionales se encaminan a crear también espacios y procesos destinados al control y regulación de flujos que implican la limitación de derechos y libertades. Promover acciones de protesta, 0 intercambio de información entre colectivos, que tengan como obje- 
tivo la lucha contra la "Europa de los campos". Difundir otras acciones y movilizaciones que tienen lugar en contra de los "campos".

15 Además de los intentos colectivos de saltar las alambradas que separan África de las ciudades españolas en el continente africano, aproximadamente cinco personas murieron por disparos producidos por las policias fronterizas españolas y marroquies. Posteriormente, millares de personas procedentes del África subsahariana fueron deportadas desde Marruecos hasta las regiones desérticas del Sahara en donde algunos fallecieron por inanición y deshidratación. "MSF localiza a más de 500 inmigrantes abandonados a su suerte en el desierto del sur de Marruecos. Los equipos de Médicos Sin Fronteras (MSF) localizaron anoche a un grupo de más de 500 inmigrantes subsaharianos abandonados a su suerte en una zona desértica situada al sur de Marruecos. Según cuentan los propios inmigrantes, la policía marroquí les conduce en autobuses y camiones hasta esta zona (situada a 600 kilómetros al sur de Oujda, donde eran abandonados anteriormente) tras ser expulsados por la Guardia Civil desde Ceuta y Melilla". Comunicado de Médicos Sin Fronteras, Barcelona/El Aouina-Souatar, 7 de octubre de 2005.

16 Declaraciones hechas al Periódico Diagonal, n. ${ }^{3}$ 39, 13 oct. -25 oct. 2006.

17 Declaraciones de una activista publicadas en Lara, Ángel Luis (2006), "Caravana europea contra la valla. Acción por la libertad de movimiento", www.ladinamo.org.

18 Esta norma municipal, inspirada en las políticas de Tolerancia Cero, tenía como objetivo criminalizar la pobreza y la inmigración persi- guiendo actividades como "la venta ambulante, el trabajo sexual, la mendicidad, otro tipo de trabajos informales (limpiadores de vidrios de los semáforos, vendedores de cerveza callejeros...) y el resto de actividades que son definidas como 'utilización abusiva del espacio público' -entre las que destacan las actividades políticas y espacios de organización de los migrantes: reuniones en la calle, reparto de panfletos, pegada de carteles, pancartas en los balcones, etc.-" (Manifiesto de la 2. ${ }^{\text {a Caravana }}$ Europea).

19 Entre otros por la Asamblea de Resistencias al Forum 2004, la Asamblea de Inmigrantes por la Regularización sin condiciones, el colectivo de trabajadoras sexuales Licit, la Plataforma contra la Especulación, la Asamblea de okupas de Barcelona y la Red Contra los Cierres de Empresas.

\section{BIBLIOGRAFÍA}

Arbide, Hibai (2005): "MayDay Barcelona: de recomposiciones y otras dudas", en AA.W., Contrapoder, 9.

Baubock, Rainer (2003): "Towards a political theory of migrant transnationalism", International Migration Review, 37(3).

Beck, U. (2001): "El mundo después del 11-S", El País, 19 octubre.

Castles, Stephen (2003): "Globalización y transnacionalismo. Implicaciones de para la incorporación de inmigrantes y para la ciudadanía", Revista de Occidente, 256, pp. 22-44.

Cohen, Robin (2006): Migration and its Enemies: Global Capital, Migrant Labour and the Nationstate, Aldershot, Ashgate.

Cohen, Robin y Shirin, Rai (2004): Global Social Movements, Londres-Nueva
York, Continuum International Publishing Group.

Davis, Mike (2008): "A modo de conclusión... El gran muro del capital. EE.UU./ México y en todas partes: cómo los paises ricos del mundo mantienen alejados de manera brutal a los pobres del mundo", en W.AA., Frontera Sur. Nuevas políticas de gestión y externalización del control de la inmigración en Europa, Virus, Barcelona, pp. 251-259.

De Lucas, Javier (2004): "Inmigrantes, extraños a la comunidad, enemigos. Ida y vuelta en la respuesta del derecho a la inmigración", Sociologia del Diritto, 2, pp. 23-34.

Della Porta, Donatella; Andretta, Massimiliano; Mosca, Lorenzo y Reiter, Herbert (2006): Globalization from Below: Transnational Activists and Protest Networks, Mineapolis-Londres, University of Minnesota Press.

Étienne, Balibar (2005): Violencias, identidades y civilidad, Gedisa, Barcelona.

Evans, Peter (2000): "Counter-Hegemonic Globalization: Transnational Networks as Political Tools for Fighting Marginalization", Contemporary sociology, 29 (1), pp. 230-241.

- (2007): Instituciones y desarrollo en la era de la globalización neoliberal, Bogotá, ILSA.

Faria, Jose Eduardo (2000): "La metamorfosis del Derecho en la reestructuración del capitalismo", Jueces para la Democracia, 39, pp. 3-12.

Glick Schiller, Nina; Basch, Linda y Szanton Blanc, Cristina (1992): Toward a Transnational Perspective on Migration, New York, New York Academy of Sciences.

Hardt, Michael y Negri, Antonio (2004): Multitud. Guía y democracia en la era del Imperio, Buenos Aires, Debate.

Juris, Jeffrey (2006): "Movimientos sociales en red: movimientos globales por una 
justicia global" en Castells, Manuel (ed.), La sociedad red: una visión global, Madrid, Alianza, pp. 415-439.

Keck, Margaret y Sikkin, Kathryn (1998): Activists beyond borders, Ithaca, Cornell University Press.

Massey, Douglas; Arango, Joaquín; Hugo, Graeme; Kouaouci, Ali; Pellegrino, Adela y Taylor, Edward (1999): Worlds in Motion: Understanding International Migration at the End of the Millennium, Oxford, Clarendon.

Portes Alejandro; Escobar, Cristina y Arana, Renelinda (2009): "Sorteando la brecha: Organizaciones transnacionales y étnicas en la incorporación política de los inmigrantes en los Estados Unidos", en Blanco, Cristina y Barbero, Iker (eds.), Pautas de asentamiento de la población inmigrante: Implicaciones y retos socio-jurídicos, Colección Derecho y sociedad, Oñati, Dykinson.

Portes, Aelajndro; Guarnizo, Luis Eduardo y Landolt, Patricia (1999) (eds.): "Trans- national Communities", special issue, Ethnic and Racial Studies 22(2).

Santos, Boaventura de Sousa (1995): Toward a New Common Sense: Law, Science and Politics in the Paradigmatic Transition, Nueva York, Routledge.

- (2005): El milenio huérfano. Ensayos para una nueva cultura política, Madrid, Trotta.

- (2009): Sociología jurídica crítica. Para un nuevo sentido común en el derecho, Madrid, Editorial Trotta.

Santos, Boaventura de Sousa y Rodríguez Garavito, César (2007): El Derecho y la Globalización desde abajo. Hacia una legalidad cosmopolita, Barcelona, Anthropos-UAM.

Smith, Michael Peter y Guarnizo, Luis Eduardo (eds.) (1998): Transnationalism from Below, New Brunswick, Transaction Publishers.

Starr, Amory (2005): Global Revolt: a Guide to the Movements against Globalization, Londres y Nueva York, Zed books.
Terray, Emmanuel (2008): "Inmigración en la UE. La política que se proclama no coincide en absoluto con la política que se aplica. La política aplicada no pretende expulsar a la gente, sino aterrorizarla", Viento sur: Por una izquierda alternativa, 98, pp. 99-107.

Vertovec, Stephen y Cohen, Robin (eds.) (1999): Migration and Transnationalism, Aldershot, Edward Elgar.

Wihtol de Wenden, Catherine (2000): ¿Hay que abrir las fronteras?, Barcelona, Bellaterra.

\section{Páginas Web consultadas:}

- http://fortresseurope.blogspot.com

- www.noborder.org

- www.deletetheborders.org

- http://thistuesday.org

- www.migreurope.org

- http://barcelona.indymedia.org/

- http://estrecho.indymedia.org 